\title{
The attributable mortality of acute respiratory distress syndrome
}

\author{
Catherine L. Auriemma ${ }^{1,2^{*}}$ (D) Kevin Delucchi ${ }^{3}$, Kathleen D. Liu ${ }^{4,5}$ and Carolyn S. Calfee $5,6,7$
}

๑) 2020 Springer-Verlag GmbH Germany, part of Springer Nature

\section{Dear Editor,}

de Grooth and colleagues, in response to our recent publication [1], expressed concern that imperfection in our risk adjustment has led to an overestimation in the ARDS-attributable fraction of mortality risk among patients with sepsis [2]. We agree that our risk adjustment is imperfect, as is the case for all models that require significant underlying assumptions. For this reason, we proactively included a directed acyclic graph to lay out the assumptions made in our strategy. In so doing, we allow for (and welcome) the thoughtful discussion on limitations to our strategy, such as raised by de Grooth and colleagues.

The authors note that we did not use a time-varying measure for severity of illness, and our results are vulnerable to time-varying disease bias. Our risk adjustment was limited by ability to include only the data we had, which did not include a daily measure of illness severity. We did perform a sensitivity analysis in which we excluded patients who died within 5 days of enrollment, excluding patients who profoundly and rapidly deteriorated to a very early death, and results were unchanged.

We did not adjust our analyses for other organ failures, beyond what is included within the APACHE and SAPS scores, as we hypothesize that other acute organ failures may lie on the indirect causal path between ARDS and death. There is a growing body of evidence showing that acute lung injury can amplify renal injury [3]. The interplay between renal and lung injury is likely bidirectional and potentially mediated through inflammation

\footnotetext{
*Correspondence: Catherine.auriemma@pennmedicine.upenn.edu ${ }^{1}$ Division of Pulmonary, Allergy, and Critical Care Medicine, Department of Medicine, Hospital of the University of Pennsylvania, 839 W. Gates, 3600 Spruce Street, Philadelphia, PA 19103-4283, USA

Full author information is available at the end of the article
}

$[4,5]$. Others have shown that multisystem organ failure can be propagated by ventilator-induced lung injury [6]. Not knowing with precision the proportion of mortality caused by other acute organ failures lies on the causal path between ARDS and mortality versus serves as a confounder makes adjustment for these variables challenging. Excluding other organ failures from the model may inflate our estimate, though we note that the APACHE and SAPS scores do incorporate acute organ failures. Fully adjusting for non-pulmonary organ failures, however, would inappropriately attenuate or fully obscure the effects of ARDS on mortality.

The authors make the important point that errors in ARDS-specific risk can have significant effects on the estimation of a necessary trial size. We agree. However, our primary conclusions still hold. One, any absolute changes in mortality by fully treating or preventing ARDS would still be relatively low. Two, trials designed to detect differences in ARDS mortality would need to be quite large. We did not provide specific numbers given limitations in the precision of our estimate. Three, trial design and efficiency could be improved by focusing enrollment on patients with severe ARDS. While the authors provide calculations showing how a trial size would differ substantially if the true value of ARDS-specific risk is half our estimate, there is no empiric data on which to base the degree of overestimation.

Establishing causality from observational data will always be challenging, and all models are inherently limited by their underlying assumptions. We are grateful that the transparency we have provided in the development of our model has prompted thoughtful discussion, and we hope it will inform improved future study design and ultimately, ongoing advancement of knowledge. 


\section{Author details}

${ }^{1}$ Division of Pulmonary, Allergy, and Critical Care Medicine, Department of Medicine, Hospital of the University of Pennsylvania, 839 W. Gates, 3600 Spruce Street, Philadelphia, PA 19103-4283, USA. ${ }^{2}$ Palliative and Advanced Illness Research (PAIR) Center, University of Pennsylvania, Philadelphia, PA, USA. ${ }^{3}$ Department of Psychiatry, University of California, San Francisco, USA. ${ }^{4}$ Division of Nephrology, Department of Medicine, University of California, San Francisco, USA. ${ }^{5}$ Department of Anesthesia, University of California San Francisco, San Francisco, CA, USA. ${ }^{6}$ Cardiovascular Research Institute, University of California, San Francisco, USA. ${ }^{7}$ Division of Pulmonary and Critical Care Medicine, Department of Medicine, University of California, San Francisco, USA.

\section{Compliance with ethical standards}

\section{Conflict of interest}

Dr. Calfee reports funding for observational research from Bayer (past) and Roche/Genentech (current), as well as consulting/advisory board services for Quark and Vasomune.

\section{Publisher's Note}

Springer Nature remains neutral with regard to jurisdictional claims in published maps and institutional affiliations.

\section{References}

1. Auriemma CL, Zhuo H, Delucchi K, Deiss T, Liu T, Jauregui A, Ke S, Vessel K, Lippi M, Seeley E, Kangelaris KN, Gomez A, Hendrickson C, Liu KD, Matthay MA, Ware LB, Calfee CS (2020) Acute respiratory distress syndromeattributable mortality in critically ill patients with sepsis. Intensive Care Med. https://doi.org/10.1007/s00134-020-06010-9

2. de Grooth HJ, Tuinman PR, Girbes ARJ (2020) The attributable mortality of acute respiratory distress syndrome. Intensive Care Med. https://doi. org/10.1007/s00134-020-06053-y

3. Husain-Syed F, Slutsky AS, Ronco C (2016) Lung-kidney cross-talk in the critically ill patient. Am J Respir Crit Care Med 194(4):402-414. https://doi. org/10.1164/rccm.201602-0420CP

4. Andres-Hernando A, Okamura K, Bhargava R, Kiekhaefer CM, Soranno D, Kirkbride-Romeo LA, Gil HW, Altmann C, Faubel S (2017) Circulating IL-6 upregulates IL-10 production in splenic CD4+T cells and limits acute kidney injury-induced lung inflammation. Kidney Int 91(5):1057-1069. https://doi.org/10.1016/j.kint.2016.12.014

5. Teixeira JP, Ambruso S, Griffin BR, Faubel S (2019) Pulmonary consequences of acute kidney injury. Semin Nephrol 39(1):3-16. https://doi. org/10.1016/j.semnephrol.2018.10.001

6. Dos Santos CC, Slutsky AS (2000) Mechanotransduction, ventilatorinduced lung injury and multiple organ dysfunction syndrome. Intensive Care Med 26(5):638-642. https://doi.org/10.1007/s001340051217

Accepted: 8 May 2020

Published online: 25 May 2020 